\title{
A New Strategy for the Synthesis of Nucleosides: One-Pot Enzymatic Transformation of D-Pentoses into Nucleosides
}

\author{
Anatoly I. Miroshnikov ${ }^{1}$, Roman S. Esipov ${ }^{1}$, Tat'yana I. Muravyova ${ }^{1}$, Irina D. Konstantinova ${ }^{1}$, \\ Ilja V. Fateev ${ }^{1}$ and Igor A. Mikhailopulo*,2
}

\author{
${ }^{I}$ Shemyakin-Ovchinnikov Institute of Bioorganic Chemistry, Russian Academy of Sciences, Moscow B-437, Russian \\ Federation, \\ ${ }^{2}$ Institute of Bioorganic Chemistry, National Academy of Sciences of Belarus, 220141 Minsk, Acad. Kuprevicha 5/2, \\ Republic of Belarus
}

\begin{abstract}
A possibility of the one-pot synthesis of purine and pyrimidine nucleosides employing pure recombinant ribokinase, phosphopentomutase and nucleoside phosphorylases in a caskade transformation of D-pentoses into nucleosides is demonstrated. Preliminary results of this study point to reliability to develop practical methods for the preparation of a number of biologically important nucleosides.
\end{abstract}

Keywords: Nucleosides, one-pot transformation of pentoses into nucleosides.

\section{INTRODUCTION}

During recent years, a chemo-enzymatic approach to the synthesis of nucleosides attracts continuously growing interest (for recent reviews, see [1]). There are three lines of investigation in this field of research, viz., (i) transglycosylation reaction consisting of the transfer of a pentofuranosyl moiety of commercially available nucleosides or prepared by chemical methods to purine or pyrimidine bases catalyzed by nucleoside phosphorylases (NP's) or $N$-deoxyribosyltransferases (DRT's) [1, 2]; (ii) biochemical (microbial, enzymatic) retro-synthesis of 2'deoxyribonucleosides [3], and (iii) chemical or chemoenzymatic synthesis of $\alpha$-D-pentofuranose 1-phosphates (PF- $\alpha 1 \mathrm{P})$ followed by the enzymatic condensation with heterocyclic bases [4]. Transglycosylation reaction was demonstrated to be a very efficient methodology for the synthesis of plenty of analogues of natural nucleosides of biological and medicinal importance; however, some limitations are well documented too $[1,2 \mathrm{a}, \mathrm{f}]$. The retrosynthesis can be employed only for the preparation of 2 'deoxy- $\beta$-D-nucleosides of natural or modified heterobases. Chemical [4a-d] and chemo-enzymatic syntheses [4e] of PF$\alpha 1 \mathrm{P}$ has attracted much attention during recent years; however, the laborious preparation of PF- $\alpha 1 \mathrm{P}$ is a serious bottleneck of this approach to the synthesis of nucleosides.

Recently, we have suggested a new strategy for the synthesis of nucleosides [5]. In the present communication, we report on the preparation of the recombinant E. coli phosphopentomutase (PPM) and preliminary results of onepot enzymatic transformation of D-ribose or 2-deoxy-Dribose into nucleosides employing pure recombinant $E$. coli

*Address correspondence to these authors at the Institute of Bioorganic Chemistry, National Academy of Sciences of Belarus, 220141 Minsk, Acad. Kuprevicha 5/2, Republic of Belarus; Tel: + 3751726781 48;

Fax: +375 1726787 61; E-mail: igor_mikhailo@yahoo.de ribokinase (RK) [D-pentose $\rightarrow$ pentose-5-phosphates (D-PF5P)], PPM [D-PF-5P $\rightarrow \alpha$-D-pentofuranose 1-phosphates $(\alpha-\mathrm{D}-\mathrm{PF}-1 \mathrm{P})]$, and nucleoside phosphorylases (NP's) ( $\alpha$-D$\mathrm{PF}-1 \mathrm{P}+$ heterobase $\rightarrow \beta$-D-nucleosides) coupled with the appropriate pyrimidine or purine heterobases (Scheme 1). The preparation of pure recombinant RK as well as uridine (UP), thymidine (TP) and purine nucleoside (PNP) phosphorylases was described by us earlier $[5,6]$.

We have earlier prepared recombinant E. coli RK and investigated its properties [5]. It is noteworthy that the chemical [7a-9] and chemo-enzymatic [4e, 7] transformations of pentoses into 5-phosphates are rather laborious and low yielding. Ribokinase from E. coli was employed for the transformation of D-ribose into Dribofuranose 5-phosphate in the chemical and enzymatic synthesis of nucleoside-5'-triphosphates with deuterium labels on the $3^{\prime}, 4^{\prime}$, and $5^{\prime}$ carbons through intermediate formation of 5-phospho-D-ribosyl $\alpha$-1-pyrophosphate (PRPP) [7b]. We have found that under optimum conditions RK catalyzes the phosphorylation of the primary hydroxyl group not only of D-ribose and 2-deoxy-D-ribose, but also of $\mathrm{D}$-arabinose and D-xylose [5]. These data prompted us to consider this reaction as the first stage in a cascade transformation of pentoses into nucleosides.

\section{RESULTS AND DISCUSSION}

The stereospecific $\mathrm{C} 5 \rightarrow \mathrm{C} 1$ translocation of phosphate catalyzed by PPM $[3 b, 10,11]$ is a reliable bridge within the strategy under investigation. With this aim in view, we have prepared recombinant PPM and studied its properties. In brief, the PPM gene $D e o B$ from $E$. coli was amplified by PCR with synthetic primers Deo- $1 b$ and Deo-2. The primers contained restriction sites $\mathrm{NcoI}$ (5'-end of the gene) and EcoRI (3'-end), respectively. PCR products were analyzed by agarose gel electrophoresis. Then, the amplified fragment was digested by restrictases $N c o$ I and EcoRI and cloned into the corresponding sites of plasmid vector pET-23d 


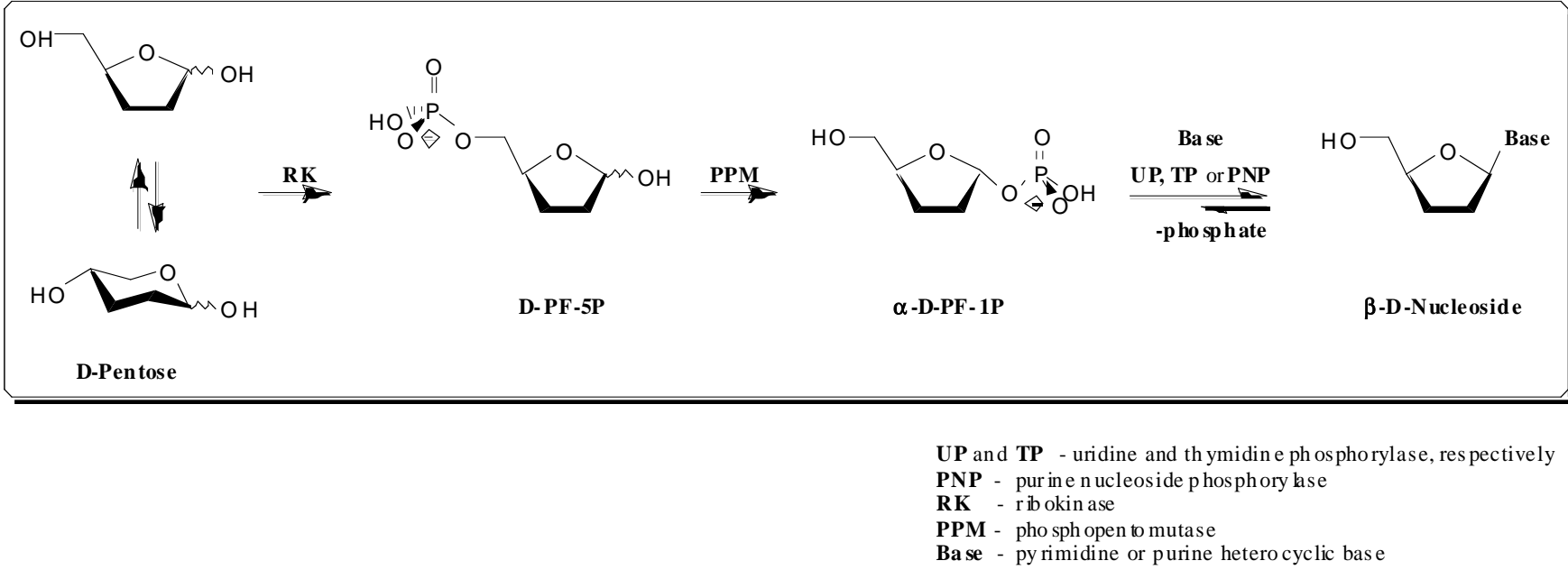

Scheme 1. One-pot transformation of D-pentoses into $\beta$-D-nucleosides through intermediate formation of respective $\alpha$-D-pentofuranose 1phosphates $(\alpha-\mathrm{D}-\mathrm{PF}-1 \mathrm{P})$.

(Novagen). The resulting plasmid pER-PPM1 was transformed into $E$. coli strain ER2566. Nucleotide sequence of the cloned fragment according to the F. Saenger method revealed no mutations.

The transformants grown at $37^{\circ} \mathrm{C}$ on the selective agar plates $(100 \mu \mathrm{g} / \mathrm{mL}$ of ampicillin) were used to inoculate an YT-medium containing $100 \mu \mathrm{g} / \mathrm{mL}$ of ampicillin. When the culture reached a density of 0.7 units at $600 \mathrm{~nm}$, expression of the recombinant enzyme was induced by the addition of 1 $\mathrm{mM}$ (final concentration) isopropyl $\beta$-D-galactopyranoside (IPTG) and incubation at $37^{\circ} \mathrm{C}$ was carried out for another 6 h. Cells were harvested by centrifugation at 4,000 rpm for 30 min at $4{ }^{\circ} \mathrm{C}$ and the expression level in each clone was analyzed by SDS-polyacrylamide gel electrophoresis. Two clones with the highest level of expression of the desired enzyme (up to $50 \%$ of the total cellular protein) were selected.

The cell pellet was resuspended in the buffer solution containing $50 \mathrm{mM}$ Tris-HCl, pH 7.7, $4 \mathrm{mM}$ EDTA, $1 \mathrm{mM}$ phenylmethyl-sulphonyl fluoride (PMSF) ( $c a .7 \mathrm{~mL}$ of the buffer per $1 \mathrm{~g}$ of cell pellet). The cells were disrupted by sonication for $5-7 \mathrm{~min}$ at $20 \mathrm{kHz}$ in ice water. The resulting cell lysate was cleared by centrifugation for $40 \mathrm{~min}$ at 15,000 rpm to afford $12 \mathrm{~mL}$ of PPM preparation (protein content $230 \mathrm{mg}$; combined PPM activity 780 units). The specific enzyme activity (vide infra) in the cleared lysate was found to be $3.4 \mu \mathrm{mol} / \mathrm{min} / \mathrm{mg}$ protein. The major portion of PPM was observed in the cleared lysate; presence of PPM in the insoluble pellet may be due to incomplete cell disruption during sonication.

The PPM of clear soluble fraction was further purified with Q-Sepharose HP chromatography to afford $12.5 \mathrm{~mL}$ of PPM solution containing $35 \mathrm{mg}$ protein with total 770 units PPM activity $(22 \mu \mathrm{mol} / \mathrm{min} / \mathrm{mg}$ protein). This PPM preparation was employed in experiments on nucleoside synthesis (vide infra). The molecular weight of PPM was estimated to be $c a$. 43,000 (cf. $[10,11])$ by SDSpolyacrylamide gel gradient electrophoresis relative to standard proteins of known molecular weight.
The PPM activity was measured spectrophotometrically by monitoring the formation of uridine resulting from the PPM catalyzed transformation of D-ribose 5-phosphate into $\alpha$-D-ribofuranose 1-phosphate followed by the condensation of the latter with uracil catalyzing by uridine phosphorylase (UP [6]) ( $c f$. [12]). The increase of molar absorptivity at 275 $\mathrm{nm}$ by going from the starting uracil to the formed uridine was found to be $\Delta \varepsilon=1800 \mathrm{M}^{-1} \mathrm{~cm}^{-1}$. One unit of PPM activity is defined as the amount of enzyme that transformed $1 \mu \mathrm{mol}$ uracil into uridine per minute at $23^{\circ} \mathrm{C}$ in the reaction mixture containing $0.1 \mathrm{M}$ Tris- $\mathrm{HCl}, 0.1 \mathrm{M} \mathrm{MnCl}_{2}, 0.05 \mathrm{mM}$ glucose 1,6-diphosphate, $7 \mathrm{mM}$ uracil, $10 \mathrm{mM}$ D-ribofuranose 5phosphate, and an excess of uridine phosphorylase (UP) (3-5 units [6]) ( $\mathrm{pH} 7.5)$; the reaction was initiated by addition of PPM.

Finally, one-pot enzymatic transformation of D-ribose or 2-deoxy-D-ribose into the pyrimidine and purine nucleosides was studied (Scheme (2)).

First of all, to assess the efficacy of PPM, we have tested the synthesis of inosine (rI) and 1-( $\beta$-D-ribofuranosyl) thymine (rT) using D-ribose 5-phosphate and the respective heterobases, hypoxanthine or thymine, as substrates and PPM and the relevant enzymes, PPM/PNP or PPM/TP, as biocatalysts. Based on the literature data [10], the following reaction conditions have been employed in these experiments after a number of preliminary tests: the molar ratio of D-ribose 5-phosphate and base was 1:1;3 mM $\mathrm{MnCl}_{2}, 10 \mathrm{mM}$ Tris, $\mathrm{pH}$ 7.5, all experiments have been performed at $20^{\circ} \mathrm{C}$.

The formation of inosine or rT was analyzed by HPLC after 1 and $24 \mathrm{~h}$. It was found that $35 \%$ of hypoxanthine is transformed into inosine after $1 \mathrm{~h}$ and its quantity only slightly enhanced after $24 \mathrm{~h}(39 \%)$; under similar time intervals, the yield of rT was 8.5 and $16.9 \%$, respectively.

Upon moving to the one-pot synthesis of nucleosides, we noted rather essential differences between that the optimal reaction conditions for RK, PPM and recombinant nucleoside phosphorylases prepared by us earlier [6]. Bearing this in mind, we have optimized the one-pot reaction conditions aiming at the finding out a compromised 

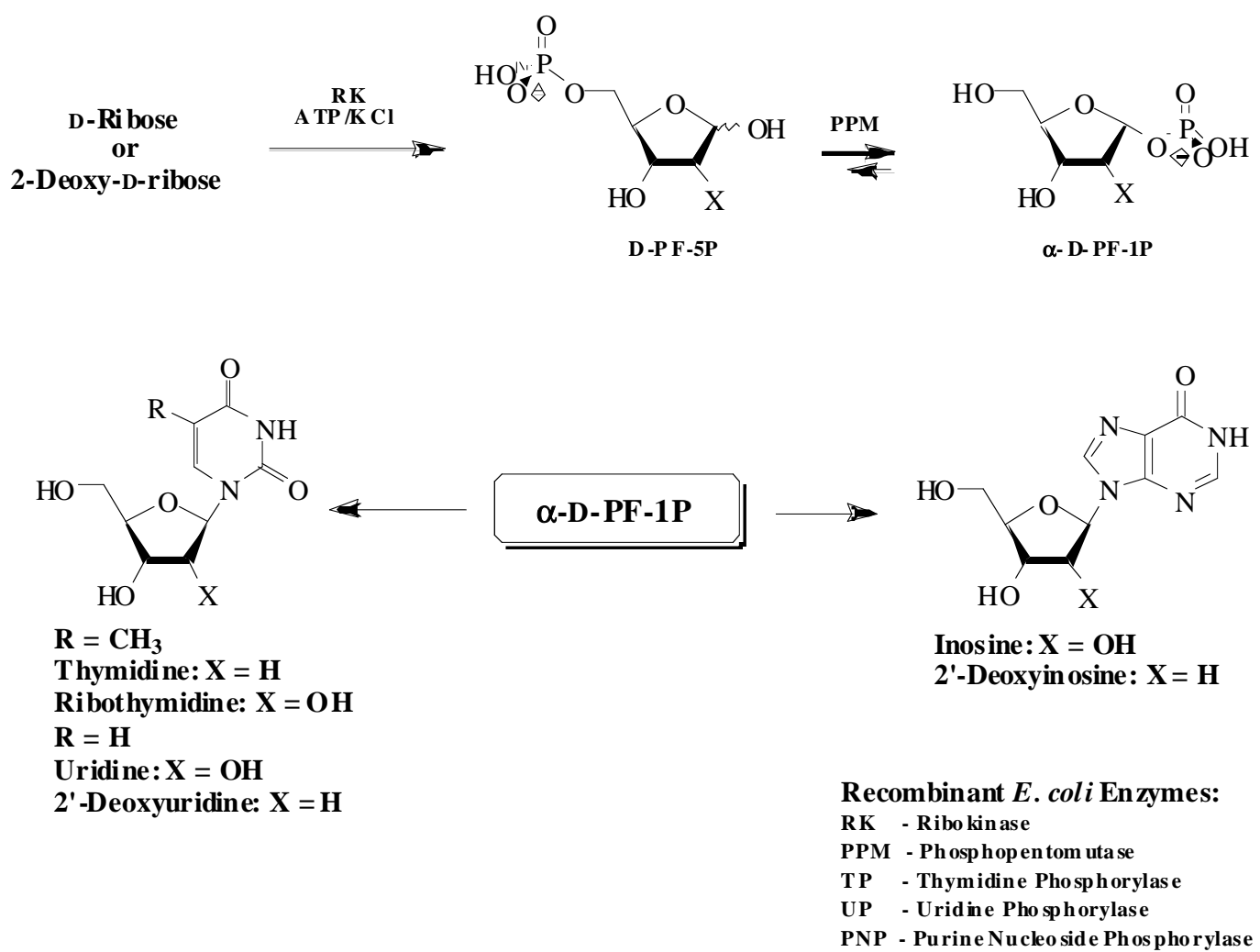

Scheme 2. One-pot transformation of D-ribose and 2-deoxy-D-ribose into pyrimidine and purine nucleosides through intermediate formation of respective $\alpha$-D-pentofuranose 1-phosphates ( $\alpha$-D-PF-1P).

composition of the components allowing satisfactory function of the enzymes under investigation. We have previously shown that magnesium and manganese ions render rather similar effect on the recombinant RK activity and in the present study the latter was employed for the activation of RK and PPM. The data on the concerted action of the aforementioned enzymes in one-pot transformation of D-ribose and 2-deoxy-D-ribose into pyrimidine and purine nucleosides are shown in Table $\mathbf{1}$.

It is remarcable that $(i)$ the formation of inosine proceeds faster $v s$ that of $2^{\prime}$-deoxyinosine and reached maximum yield after 30 min (Table 1; Fig. (1)), and (ii) the synthesis of $2^{\prime}$ deoxyribonucleosides of purines by the transglycosylation reaction procceds with higher efficiency compared to that of ribonucleosides [13].

The formation of thymidine proceeds with higher efficacy and gives rise to the higher final yield of thymidine $v s$ that of rT (Table 1; Fig. (2)). The observed differences in the formation of thymidine and rT may be explained by the lower substrate activity of $\alpha$-D-ribofuranose 1-phosphate $v s$ its 2-deoxy-counterpart for thymidine phosphorylase (TP). In harmony with this suggestion is the formation of

Table 1. Progress of Nucleoside Syntheses in the Cascade One-Pot Enzymatic Reactions at $20^{\circ} \mathrm{C}$ [Content of the Corresponding Nucleoside (\%) in the Reaction Mixture $v s$ Time of Reaction ${ }^{\mathrm{a}, \mathrm{b}}$ ]

\begin{tabular}{|c|c|c|c|c|}
\hline Time of Reaction, $h$ & $\begin{array}{c}\text { Inosine } \\
(\mathbf{r I})\end{array}$ & $\begin{array}{l}\text { 2'-Deoxy-inosine } \\
\text { (dI) }\end{array}$ & $\begin{array}{c}\text { Thymidine (dT)/2'-Deoxyuridine } \\
(\mathrm{dU})^{\mathrm{c}}\end{array}$ & $\begin{array}{c}\text { 1-( } \beta \text {-D-Ribofuranosyl)-thymine }(\mathrm{rT}) / \\
\text { Uridine }(\mathrm{rU})^{\mathrm{c}}\end{array}$ \\
\hline 0.5 & 45.9 & 18.8 & $14.5 / 0.9$ & $4.7 / 27.6$ \\
\hline 1 & 46.1 & 27.3 & 17.6/1.1 & $8.5 / 26.6$ \\
\hline 24 & 38.4 & 38.3 & - & - \\
\hline 44 & - & - & $34.7 / 33.2$ & $19.9 / 17.5$ \\
\hline 96 & 29.4 & 34.4 & - & - \\
\hline
\end{tabular}

${ }^{\mathrm{a}} \mathrm{All}$ the reactions have been run under standard conditions. ${ }^{\mathrm{b}}$ Standard Reaction Conditions: total volume of the reaction mixture $2 \mathrm{~mL} ; 2 \mathrm{mM} \mathrm{ATP}, 50 \mathrm{mM} \mathrm{KCl}, 3 \mathrm{mM} \mathrm{MnCl}, 20$ $\mathrm{mM}$ Tris $\cdot \mathrm{HCl}$ ( $\mathrm{pH} 7.5), 2 \mathrm{mM}$ pentose, $2 \mathrm{mM}$ heterobase; run at $20^{\circ} \mathrm{C}$; enzymes (respective units): ribokinase 7.65; phosphopentomutase 3.9 ; thymidine phosphorylase 4.5 ; uridine phosphorylase 5.4; purine nucleoside phosphorylase 4.68. HPLC Analyses: Breeze chromatograph (Waters, USA); column: Nova-Pak C18, 4 um, $4.6 \times 150$ mm; isocratic elution with $1.4 \%$ acetonitrile and $0.1 \%$ TFA at a flow rate of $1 \mathrm{~mL} / \mathrm{min}$, run time $15 \mathrm{~min}$; UV-detector, eluates were monitored at $254 \mathrm{~nm}$; retention times, $R_{\mathrm{t}}$ (min): hypoxanthine - 2.7 ; inosine $-5.4 ; 2^{\prime}$-deoxyinosine - 6.5; thymine - 3.7; thymidine - 8.3; 1 -( $\beta$-D-ribofuranosyl)thymine -5.4 ; uracil - 2.3; uridine - 3.1; 2'-deoxyuridine - 4.2. All the reference nucleosides have been prepared earlier or from commercial sources. ${ }^{\mathrm{c}}$ Thymidine (TP) and uridine (UP) phosphorylases have been employed for the synthesis of thymine and uracil nucleosides, respectively. 


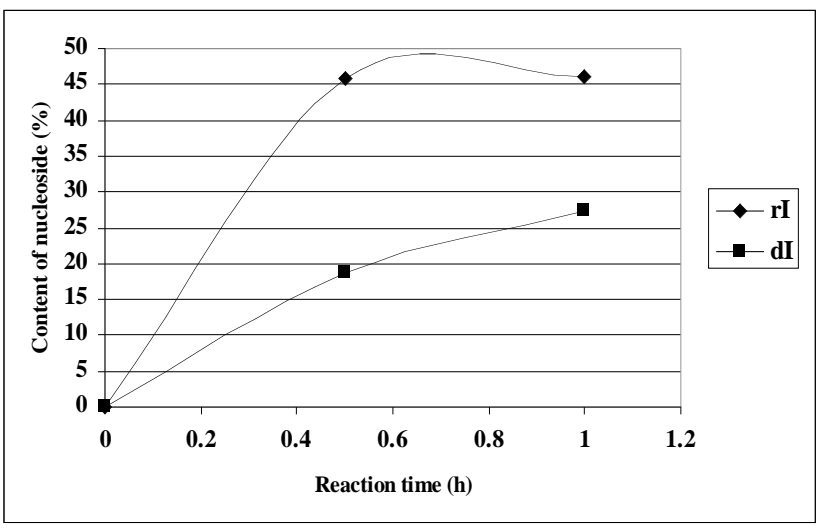

Fig. (1). Progress of the synthesis of hypoxanthine nucleosides in the cascade one-pot enzymatic reactions from the relevant pentoses.

corresponding uracil nucleosides catalyzed by uridine phosphorylase (UP). Indeed, as might be expected, $\alpha-\mathrm{D}$ ribofuranose 1-phosphate manifests much higher substrate activity towards UP vs 2-deoxy- $\alpha$-D-ribofuranose 1phosphate. However, the final concentration of uridine is $c a$. half of that of $2^{\prime}$-deoxyuridine. Interplay of a number of factors contributing to the reaction pathway may be responsible for this result.

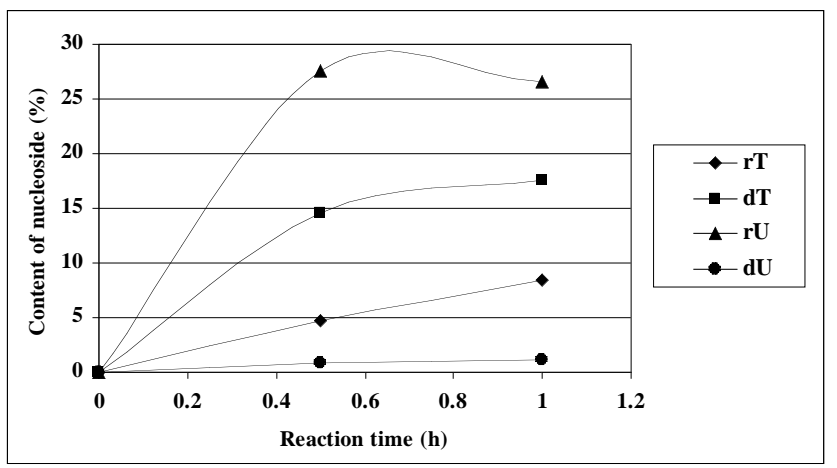

Fig. (2). Progress of the synthesis of pyrimidine nucleosides in the cascade one-pot enzymatic reactions from the relevant pentoses.

In conclusion, a possibility of the one-pot synthesis of purine and pyrimidine nucleosides employing pure recombinant ribokinase, phosphopentomutase and nucleoside phosphorylases in a cascade transformation of Dpentoses into nucleosides was demonstrated. Taking into account the functional peculiarities of the enzymes under consideration, a careful optimization of the reaction conditions is necessary to achieve high yield of the desired nucleosides. Note that all the reactions of the present study have been run at an 1:1 molar ratio of pentose and heterobase and at $20^{\circ} \mathrm{C}$. The studies directed towards assessment of the scope and limitations of this strategy are now in progress. Preliminary results of this study point to reliability to develop practical methods for the preparation of a number of biologically important nucleosides.

\section{ACKNOWLEDGEMENTS}

Financial support by the International Science and Technology Centre (project \#B-1640) and Foundations for basic research of Russia and Belarus is gratefully acknowledged. IAM is thankful to the Alexander von Humboldt-Stiftung (Bonn - Bad-Godesberg, Germany) for partial financial support of this study.

\section{REFERENCES}

[1]

a) Mikhailopulo, I.A. Biotechnology of nucleic acid constituents State of the art and perspectives. Curr. Org. Chem, 2007, 11, 307335; b) Lewkowics, E.S.; Iribarren, A.M. Nucleoside phosphorylases. Curr. Org. Chem, 2006, 10, 1197-1215.

[2] a) Roivainen, J.; Elizarova, T.; Lapinjoki, S.; Mikhailopulo, I.A.; Esipov, R.S.; Miroshnikov, A.I. An enzymatic transglycosylation of purine bases. Nucleosides Nucleotides Nucleic Acids, 2007, 26, 905-909; b) Barai, V.N.; Zinchenko, A.I.; Eroshevskaya, L.A.; Zhernosek, E.V.; De Clercq, E.; Mikhailopulo, I.A. Chemoenzymatic synthesis of 3-deoxy- $\beta$-D-ribofuranosyl purines. Helv. Chim. Acta, 2002, 85, 1893-1900; c) Barai, V.N.; Zinchenko, A.I.; Eroshevskaya, L.A.; Kalinichenko, E.N.; Kulak, T.I.; Mikhailopulo, I.A. A universal biocatalyst for the preparation of base- and sugar-modified nucleosides via an enzymatic transglycosylation. Helv. Chim. Acta, 2002, 85, 1901-1908; d) Kaminski, P.A.; Dacher, P.; Dugue, L.; Pochet, S. In vivo reshaping the catalytic site of nucleoside 2'- deoxyribosyltransferase for dideoxy- and didehydronucleosides via a single amino acid substitution. J. Biol. Chem, 2008, 283, 20053-20059; e) Anand, R.; Kaminski, P.A.; Ealick, S.E. Structures of purine 2'deoxyribosyltransferase, substrate complexes, and the ribosylated enzyme intermediate at 2.0 A resolution. Biochemistry, 2004, 43, 2384-2393.

[3] a) Ouwerkerk, N.; van Boom, J.H.; Lugtenburg, J.; Raap, J. Chemo-enzymatic synthesis of thymidine 13C-labelled in the 2'deoxyribose moiety. Eur. J. Org. Chem, 2000, 861-866; b) Ouwerkerk, N.; Steenweg, M.; De Ruijter, M.; Brouwer, J.; van Boom, J.H.; Lugtenburg, J.; Raap, J. One-pot two-step enzymatic coupling of pyrimidine bases to 2-deoxy-D-ribose-5-phosphate. A new strategy in the synthesis of stable isotope labeled deoxynucleosides. J. Org. Chem, 2002, 67, 1480-1489; c) Ogawa, J.; Saito, K.; Sakai, T.; Horinouchi, N.; Kawano, T.; Matsumoto, S.; Sasaki, M.; Mikami, Y.; Shimizu, S. Microbial production of 2deoxyribose 5-phosphate from acetaldehyde and triosephosphate for the synthesis of 2'-deoxyribonucleosides. Biosci. Biothechnol. Biochem, 2003, 67, 933-936; d) Ishige, T.; Honda, K.; Shimizu, S. Whole organism biocatalysis. Curr. Opin. Chem. Biol, 2005, 9, 174-180; e) Horinouchi, N.; Ogawa, J.; Kawano, T.; Sakai, T.; Saito, K.; Matsumoto, S.; Sasaki, M.; Mikami, Y.; Shimizu, S. Biochemical retrosynthesis of 2'-deoxyribonucleosides from glucose, acetaldehyde, and a nucleobase. Appl. Microbiol. Biotechnol, 2006, 71, 615-621; f) Horinouchi, N.; Ogawa, J.; Kawano, T.; Sakai, T.; Saito, K.; Matsumoto, S.; Sasaki, M.; Mikami, Y.; Shimizu, S. Efficient production of 2-deoxyribose 5phosphate from glucose and acetaldehyde by coupling of the alcoholic fermentation system of baker's yeast and deoxyriboaldolase-expressing Escherichia coli. Biosci. Biotechnol. Biochem, 2006, 70, 1371-1378; g) Horinouchi, N.; Ogawa, J.; Kawano, T.; Sakai, T.; Saito, K.; Matsumoto, S.; Sasaki, M.; Mikami, Y.; Shimizu, S. One-pot microbial synthesis of 2'-deoxyribonucleoside from glucose, acetaldehyde, and a nucleobase. Biotechnol. Lett, 2006, $28,877-881$.

[4] a) Komatsu, H.; Awano, H. First stereoselective synthesis of 2deoxy- $\alpha$-D-ribosyl-1-phosphate: Novel application of crystallization-induced asymmetric transformation. J. Org. Chem, 2002, 67, $5419-5421$; b) Komatsu, H.; Ikeda, I. Synthesis of 2-deoxy- $\beta$-Dribose 1-phosphate, NMR comparison and its enzymatic activity for structural elucidation of synthetic $\alpha$-isomer. Nucleosides Nucleotides Nucleic Acids, 2003, 22, 1685-1686; c) Komatsu, H.; Araki, T. Chemo-enzymatic synthesis of 2',3'-dideoxy-3'-fluoro- $\beta$ D-guanosine via 2,3-dideoxy-3-fluoro- $\alpha$-D-ribose 1-phosphate. Tetrahedron Lett, 2003, 44, 2899-2901; d) Komatsu, H.; Awano, H.; Ishibashi, H.; Oikawa, I.; Araki, T. Chemo-enzymatic syntheses of natural and unnatural 2'-deoxynucleosides. Nucleic Acids Res. Suppl. No. 3, 2003, 101-102; e) Taverna-Porro, M.; Bouvier, L.A.; Pereira, C.A.; Montserrat, J.M.; Iribarren, A.M. Chemoenzymatic preparation of nucleosides from furanoses. Tetrahedron Lett, 2008, 49, 2642-2645.

[5] Chuvikovsky, D.V.; Esipov, R.S.; Skoblov, Y.S.; Chupova, L.A.; Muravyova, T.I.; Miroshnikov, A.I.; Lapinjoki, S.; Mikhailopulo, 
I.A. Ribokinase from E. coli: Expression, purification, and substrate specificity. Bioorg. Med. Chem, 2006, 14, 6327-6332.

[6] Esipov, R.S.; Gurevich, A.I.; Chuvikovsky, D.V.; Chupova, L.A.; Muravyova, T.I.; Miroshnikov, A.I. Overexpression of Escherichia coli genes encoding nucleoside phosphorylases in the pET/BI21(DE3) system yields active recombinant enzymes. Protein Expres. Purif, 2002, 24, 56-60.

[7] a) Gross, A.; Abril, O.; Lewis, J.M.; Geresh, S.; Whitesides, G.M. Practical synthesis of 5-phospho-D-ribosyl $\alpha$-1-pyrophosphate (PRPP): Enzymatic routes from ribose 5-phosphate or ribose. $J$. Am. Chem. Soc, 1983, 105, 7428-7434, and references cited therein; b) Tolbert, T.J.; Williamson, J.R. Preparation of specifically deuterated RNA for NMR studies using a combination of chemical and enzymatic synthesis. J. Am. Chem. Soc., 1996, $118,7929-7940$

[8] Graham, S.M.; Pope, S.C. Selective phosphitylation of the primary hydroxyl group in unprotected carbohydrates and nucleosides. Org. Lett., 1999, 1, 733-736, and references cited therein.

[9] Ahmadibeni, Y.; Parang, K. Solid-phase reagents for selective monophosphorylation of carbohydrates and nucleosides. J. Org. Chem., 2005, 70, 1100-1103.
[10] Hammer-Jespersen, K.; Munch-Petersen, A. Phosphodeoxyribomutase from Escherichia coli. Purification and some properties. Eur. J. Biochem, 1970, 17, 397-407; Leer, J.C.; Hammer-Jespersen, K. Multiple forms of phosphodeoxyribomutase from Escherichia coli. Physical and chemical characterization. Biochemistry, 1975, 14, 599-607.

[11] Rashid, N.; Imanaka, H.; Fukui, T.; Atomi, H.; Imanaka, T. Presence of a novel phosphopentomutase and a 2-deoxyribose 5phosphate aldolase reveals a metabolic link between pentoses and central carbon metabolism in the hyperthermophilic archaeon Thermococcus kodakaraensis. J. Bacteriol., 2004, 186, 4185-4191.

[12] a) Tozzi, M.G.; Catalani, R.; Ipata, P.L.; Mura, U. A coupled optical enzyme assay for phosphopentomutase. Anal. Biochem, 1982, 123, 265-269; b) Barbas, III, C.F.; Wong, C.-H. Overexpression and substrate specificity studies of phosphodeoxyribomutase and thymidine phosphorylase. Bioorg. Chem, 1991, 19, 261-269.

[13] Mikhailopulo, I.A.; Zinchenko, A.I.; Bokut, S.B.; Dudchik, N.V.; Barai, V.N.; Kalinichenko, E.N.; Rosemeyer, H.; Seela, F. 1-deaza and 3-deazapurines in the reaction of microbiological transglycosylation. Biotechnol. Lett, 1992, 14, 885-890.

(C) Miroshnikov et al.; Licensee Bentham Open.

This is an open access article licensed under the terms of the Creative Commons Attribution Non-Commercial License (http://creativecommons.org/licenses/by-nc/3.0/) which permits unrestricted, non-commercial use, distribution and reproduction in any medium, provided the work is properly cited. 